\title{
Do Group 1 metal salts form deep eutectic solvents?
}

\author{
A. P. Abbott, ${ }^{* a}$ C. D’Agostino, ${ }^{* b}$ S. J. Davis, ${ }^{a}$ L. F. Gladden ${ }^{b}$ and M. D. Mantle ${ }^{b}$ \\ ${ }^{a}$ Department of Chemistry, University of Leicester, Leicester LE1 7RH, UK. \\ ${ }^{b}$ Department of Chemical Engineering and Biotechnology, University of Cambridge, \\ Pembroke Street, Cambridge CB2 3RA, UK.
}

\begin{abstract}
Mixtures of metal salts such as $\mathrm{ZnCl}_{2}, \mathrm{AlCl}_{3}$ and $\mathrm{CrCl}_{3} \cdot 6 \mathrm{H}_{2} \mathrm{O}$ form eutectic mixtures with complexing agents, such as urea, liquids. The aim of this research was to see if alkali metal salts also formed eutectics in the same way. It is shown that only a limited number of sodium salts form homogeneous liquids at ambient temperatures and then only with glycerol. None of these mixtures showed eutectic behaviour but the liquids showed the physical properties similar to the group of mixtures classified as deep eutectic solvents. This study focussed on four sodium salts: $\mathrm{NaBr}, \mathrm{NaOAc}, \mathrm{NaOAc} \cdot 3 \mathrm{H}_{2} \mathrm{O}$ and $\mathrm{Na}_{2} \mathrm{~B}_{4} \mathrm{O}_{7} \cdot 10 \mathrm{H}_{2} \mathrm{O}$. The ionic conductivity and viscosity of these salts with glycerol were studied, and it was found that unlike previous studies of quaternary ammonium salts with glycerol, where the salt decreased the viscosity, most of the sodium salts increased the viscosity. This suggests that sodium salts have a structure making effect on glycerol. This phenomenon is probably due to the high charge density of $\mathrm{Na}^{+}$, which coordinates to the glycerol. ${ }^{1} \mathrm{H}$ and ${ }^{23} \mathrm{Na} \mathrm{NMR}$ diffusion and relaxation methods have been used to understand the molecular dynamics in the glycerol-salt mixtures, and probe the effect of water on some of these systems. The results reveal a complex dynamic behaviour of the different species within these liquids. Generally, the translational dynamics of the ${ }^{1} \mathrm{H}$ species, probed by means of PFG NMR diffusion coefficients, is in line with the viscosity of these liquids. However, ${ }^{1} \mathrm{H}$ and ${ }^{23} \mathrm{Na} T_{1}$ relaxation measurements suggest that the Na-containing species also play a crucial role in the structure of the liquids.
\end{abstract}

Key words: Deep Eutectic Solvents, PFG NMR, NMR relaxation, conductivity, viscosity 


\section{Introduction}

Deep Eutectic Solvents (DES) are mixtures of Lewis and Brönsted acids and bases. The most commonly studied systems are those composed of quaternary ammonium salts and hydrogen bond donors such as amides, alcohols or acids. ${ }^{1,2}$ The depression of freezing point for some mixtures can be up to $200{ }^{\circ} \mathrm{C}$. Many applications of these compounds have already been studied including their use as: catalysts, solvents, extraction media and media to carry out electrochemical processes. A comprehensive review on the properties and applications of DESs has recently been published. ${ }^{3}$

A variety of metal salts e.g. $\mathrm{ZnCl}_{2}$ and $\mathrm{AlCl}_{3}$ and metal salt hydrates e.g. $\mathrm{CrCl}_{3} \cdot 6 \mathrm{H}_{2} \mathrm{O}$ have been shown to form eutectic mixtures with compounds such as urea. ${ }^{45}$ Most form ionic species due to disproportionation of the metal salt:

e.g. $2 \mathrm{AlCl}_{3}+$ urea $\rightarrow\left[\mathrm{AlCl}_{2} \text {.urea }\right]^{+}+\mathrm{AlCl}_{4}^{-}$

These liquids have been studied for metal deposition applications. ${ }^{6}$ Gambino et l. $^{7}$ have shown that mixtures of alkali metal halides with urea can form eutectic mixtures with typical melting points greater than $120{ }^{\circ} \mathrm{C}$; however, the systems were not suitable for the applications tested. Mjalli et l. $^{8}$ applied the same methodology to mixtures of potassium carbonate and glycerol, or ethylene glycol, and found that a 1:4 respective molar mixture of potassium carbonate and glycerol formed a colourless liquid at room temperature, with the potential application as a $\mathrm{CO}_{2}$ capture medium. ${ }^{8}$

Ideally, a DES based on a concentrated mixture of $\mathrm{NaCl}$ and glycerol would be the most economically viable DES. ${ }^{9}$ Unfortunately, $\mathrm{NaCl}$ has a relatively low solubility in glycerol (83 $\mathrm{g} \mathrm{kg}^{-1}$ of glycerol), which is not sufficiently concentrated enough to be compared against DES and ILs. ${ }^{10}$ DESs exhibit rather complex behaviour; in particular, the presence of several molecular and ionic species makes these systems very interesting to study. Diffusion often does not obey the classical Stokes Einstein model and it was suggested other factors such as the amount of free volume in the liquid and size of "hole", are important factor in controlling the motion of these species. ${ }^{11}$ Initial studies on DESs have been carried out to understand the dynamics of molecular and ionic species and see how these relate to macroscopic properties such as viscosity and electric conductivity. ${ }^{12}$ Recent diffusion studies on aqueous choline chloride-based DES were able to show that some of these liquids are inhomogeneous at a macroscopic level and it was observed that the addition of water significantly changes the molecular and ionic interactions between the different species. ${ }^{13}$ For example, in some cases, 
the hydroxyl protons of the hydrogen bond donor behave differently from its parent molecule when water is added to the system.

Electrical conductivity, density and viscosity measurements of relatively dilute alkali metal halides and glycerol have been previously carried out. ${ }^{14}$ In this study, very concentrated saltglycerol systems have been studied and their properties are compared to deep eutectic solvents. NMR diffusion and relaxation studies have been carried out to understand the dynamics of molecular and ionic species in sodium-based DES. ${ }^{1} \mathrm{H}$ PFG NMR diffusion and ${ }^{1} \mathrm{H}$ and ${ }^{23} \mathrm{Na} T_{1}$ relaxation methods were used to understand translational and rotational dynamics of molecular and ionic species, including $\mathrm{Na}^{+}$ions and see how microscopic behaviour correlates with the viscous properties of these fluids in order to understand what are the main factors affecting the macroscopic behaviour of these fluids.

\section{Experimental}

Glycerol (Fisher Scientific) was heated to $50{ }^{\circ} \mathrm{C}$ and mixed with one of the four salts NaOAc, (Fisher Scientific) $\mathrm{NaBr}$, (Sigma-Aldrich) $\mathrm{Na}_{2} \mathrm{~B}_{4} \mathrm{O}_{7} \cdot 10 \mathrm{H}_{2} \mathrm{O}$ (Sigma-Aldrich) or $\mathrm{NaOAc} \cdot 3 \mathrm{H}_{2} \mathrm{O}$ (Fisher Scientific) using an overhead stirrer (Stuart Scientific, ss10, $500 \mathrm{rpm}$ ) until all the components formed a homogeneous liquid phase. All liquids were stored at $50{ }^{\circ} \mathrm{C}$. The mixtures salt/glycerol are labelled as $\mathrm{NaOAc}, \mathrm{NaBr}, \mathrm{Na}_{2} \mathrm{~B}_{4} \mathrm{O}_{7} \cdot 10 \mathrm{H}_{2} \mathrm{O}$ and $\mathrm{NaOAc} \cdot 3 \mathrm{H}_{2} \mathrm{O}$.

The viscosities of all the ionic solvents were measured using a rotational viscometer (Brookfield DV-II+PRO), fitted with a temperature probe. Samples were heated to $45{ }^{\circ} \mathrm{C}$ and viscosity measurements were taken down to $25{ }^{\circ} \mathrm{C}\left( \pm 1{ }^{\circ} \mathrm{C}\right)$. Ionic solvents were tested for non-Newtonian fluid behaviour using the above instrument and apparatus over the viscometer rotation speed range 10-200 rpm. Sample viscosity was recorded for 10 minutes for each rotation speed to provide a stable measurement. Where error bars are not obvious they are within the dimensions of the plot symbol.

The electrical conductivities of all the ionic solvents were measured using a conductivity probe (Jenway 4510 , cell constant $\mathrm{K}=0.96$ ), which was fitted with an integral temperature probe. Conductivity was measured over the temperature range $25-45^{\circ} \mathrm{C}\left( \pm 1{ }^{\circ} \mathrm{C}\right)$.

Glass transition temperatures were determined using a Differential Scanning Calorimeter (Mettler Toledo, DSC1) controlled by STARe version 12.10 software. The mass of each sample ranged between 5 - $20 \mathrm{mg}$, and was sealed inside a $40 \mu \mathrm{Al}$ pan (Mettler Toledo) with a vent hole pierced into the lid. Samples were cooled to $-140{ }^{\circ} \mathrm{C}$ at a rate of $10{ }^{\circ} \mathrm{C} \mathrm{min}^{-1}$, then held at $-140{ }^{\circ} \mathrm{C}$ for $10 \mathrm{~min}$ and then heated up to $25{ }^{\circ} \mathrm{C}$ at a rate of $5{ }^{\circ} \mathrm{C} \mathrm{min}{ }^{-1}$. All experiments 
were carried out under a $\mathrm{N}_{2}$ atmosphere. The resulting theromgrams showed an endothermic peak corresponding to the glass transition of the samples.

All NMR measurements were conducted on a Bruker DMX 300 spectrometer operating at a frequency of $300.13 \mathrm{MHz}$. A diffusion diff-30 probe equipped with gradient coils capable to produce a maximum magnetic field gradient in the $z$-direction of up to $11.76 \mathrm{~T} \mathrm{~m}^{-1}$ was used for both diffusion and relaxation measurements, using ${ }^{1} \mathrm{H}$ and ${ }^{23} \mathrm{Na}$ resonant coils for ${ }^{1} \mathrm{H}$ and ${ }^{23} \mathrm{Na}$ NMR measurements respectively. ${ }^{1} \mathrm{H}$ PFG NMR measurements were conducted using the APGSTE (alternating pulsed gradient stimulated echo) pulse sequence with a homospoil gradient, which has the advantage of minimizing the effect of any possible background gradient present in the sample.

The NMR signal attenuation, $E(g) / E_{0}$ is related to the experimental variables and the diffusion coefficient $D$ according to:

$$
\frac{E(g)}{E_{0}}=\exp \left[-D \gamma_{H}^{2} g^{2} \delta^{2}\left(\Delta-\frac{\delta}{3}\right)\right]
$$

where $E(g)$ and $E_{0}$ are the NMR signal in the presence and absence of the gradient pulse, respectively; $\gamma_{H}$ is the gyromagnetic ratio of the nucleus being studied (i.e., ${ }^{1} \mathrm{H}$ in our case), $g$ is the strength of the gradient pulse of duration $\delta$, and $\Delta$ is the observation time. The observation time for diffusion was fixed to $\Delta=100 \mathrm{~ms}$ with values of $\delta$ in the range $1-4 \mathrm{~ms}$. The magnitude of $g$ was linearly varied and up to sixteen points were acquired for each diffusion measurement. Maximum gradient values of up to $11.50 \mathrm{~T} \mathrm{~m}^{-1}$ were necessary to reach the required signal attenuation due to the very low diffusivity observed for some of the species present in these samples. The diffusion coefficients $D$ can be calculated by fitting Equation (1) to the experimental data.

${ }^{1} \mathrm{H}$ and ${ }^{23} \mathrm{Na} T_{1}$ relaxation measurements were performed using the inversion recovery pulse sequence using a list of sixteen variable delay times. The $T_{1}$ relaxation time constant was obtained by fitting the experimental data to the equation:

$$
S(t)=S_{0}\left[1-2 \exp \left(-\frac{t}{T_{1}}\right)\right]
$$


where $S_{0}$ is the NMR signal at equilibrium (i.e., initial time) and $S(t)$ is the NMR signal recorded after a delay time $t$. NMR measurements were conducted a variable temperature in the range $25-65^{\circ} \mathrm{C}$ and the temperature was controlled by a BVT 3000 control unit.

\section{Results and discussion}

\section{Component Selection}

Figure 1 shows a selection of group 1 and group 2 metal salts mixed with either: urea, xylitol (an example of a complex sugar alcohol) and glycerol. All of the mixtures in Figure 1 were heated to $100{ }^{\circ} \mathrm{C}$ for 2 hours with intermittent shaking, and all systems were tested at a 1:4 salt to glycerol molar ratio, except for $\mathrm{NaCl}$ and $\mathrm{KCl}$, which were tested at a ratio of 1:8. Of the metal salts mixed with urea in Figure 1 only $\mathrm{Na}_{2} \mathrm{~B}_{4} \mathrm{O}_{7} \cdot 10 \mathrm{H}_{2} \mathrm{O}$ and $\mathrm{MgCl}_{2} \cdot 6 \mathrm{H}_{2} \mathrm{O}$ showed signs of partial liquid formation, whereas all of the other salts tested remained as two separate solid phases. Marginally better miscibility was achieved when urea was substituted for xylitol, but none of the systems investigated completely formed liquids. When xylitol was substituted for glycerol, all of the systems investigated formed colourless liquids at $100{ }^{\circ} \mathrm{C}$, which remained liquid upon cooling to room temperature. In no cases was the freezing point of the mixture below that of pure glycerol and so it can be concluded that salts of groups 1 and 2 do not form eutectic mixtures in the same way as salts such as zinc chloride and aluminium chloride. . $^{4}$

Considering the research from Gambino et al., ${ }^{7}$ many of the systems tested in Figure 1 may have fully formed if heated to over $150{ }^{\circ} \mathrm{C}$, but further heating would have resulted in decomposition of urea. Also, in cases where a colourless liquid formed at $100{ }^{\circ} \mathrm{C}$, the system formed a hard glass at room temperature, which means thermo-physical measurements at room temperature would be impractical. From the results shown in Figure 1, mixtures of: $\mathrm{NaBr}, \mathrm{NaOAc}, \mathrm{NaOAc} \cdot 3 \mathrm{H}_{2} \mathrm{O}$ or $\mathrm{Na}_{2} \mathrm{~B}_{4} \mathrm{O}_{7} \cdot 10 \mathrm{H}_{2} \mathrm{O}$ with glycerol were investigated further and their thermo-physical properties were studied as a function of salt concentration. 


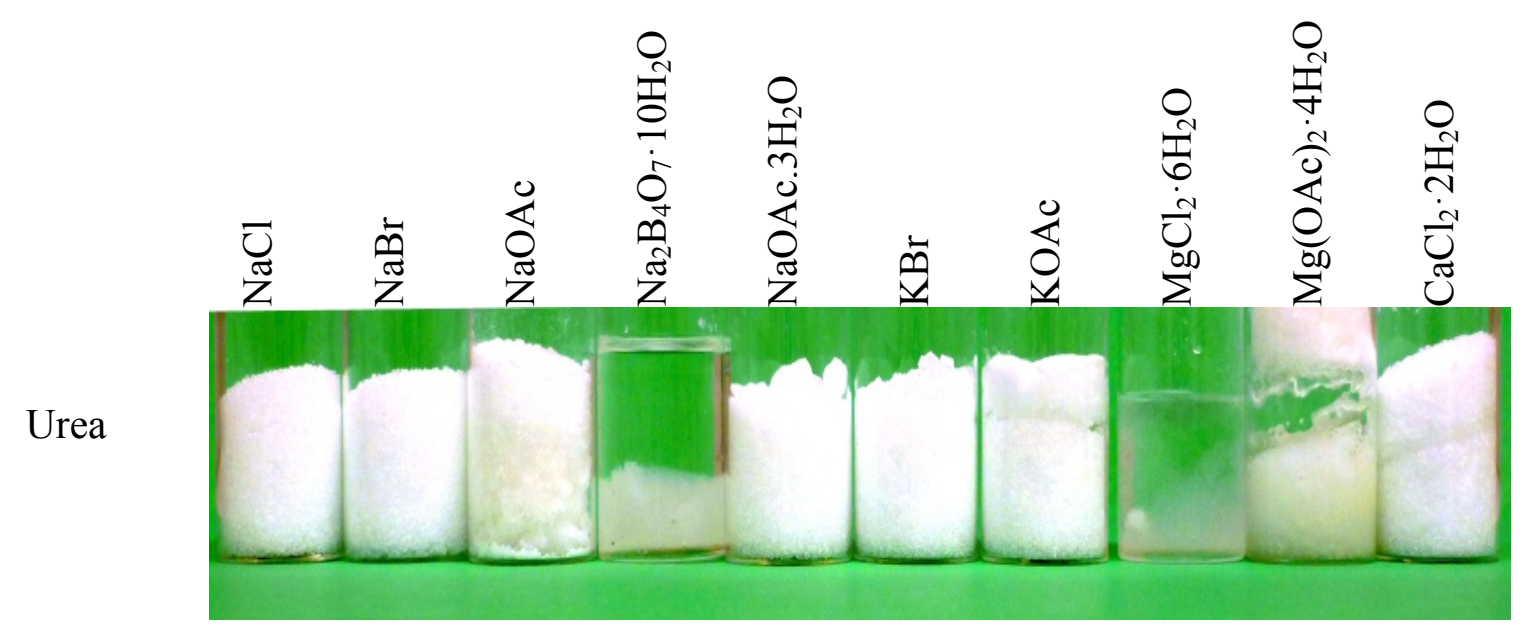

Xylitol

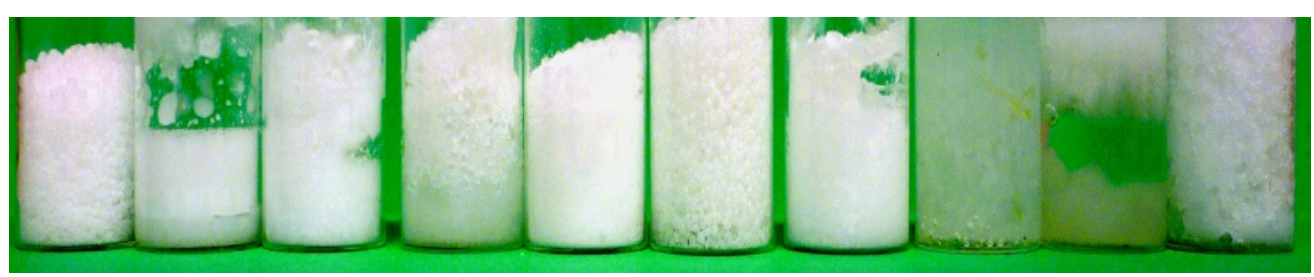

Glycerol

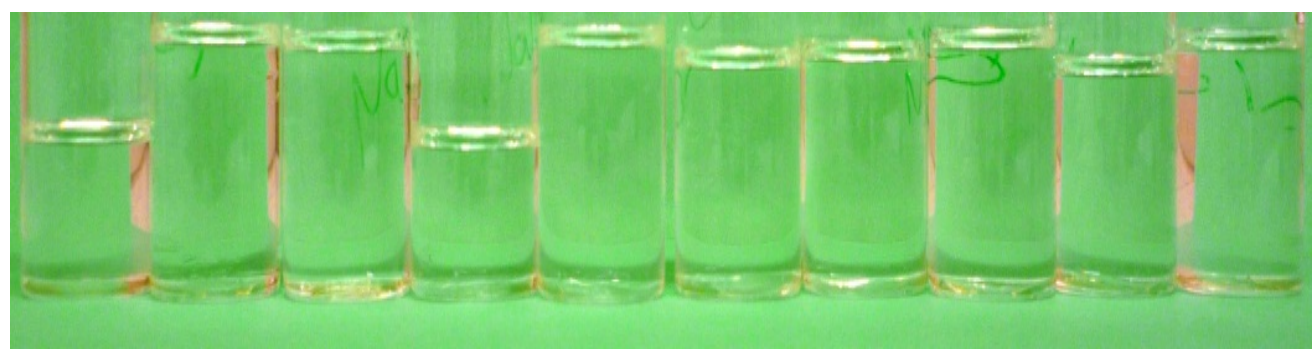

Figure 1. A selection of group 1 and group 2 metal salts mixed with either: urea, xylitol or glycerol. All systems tested were a 1 salt: $4 \mathrm{HBD}$ molar ratio or to, except for $\mathrm{NaCl}$ and $\mathrm{KCl}$, which were tested at a ratio of 1:8.

\section{Phase Behaviour}

Figure 2 shows the glass transition temperature for a range of sodium salts mixed with glycerol in the concentration range $20 \mathrm{mM}$ to $4 \mathrm{M}$. All measurements were made using differential scanning calorimetry (DSC). True melting points were not observed, which is common in ILs and some DES as solidification kinetics are slow, and tend to only form glasses. ${ }^{15}$ Mixtures of $\mathrm{NaOAc}, \mathrm{NaBr}, \mathrm{Na}_{2} \mathrm{~B}_{4} \mathrm{O}_{7} \cdot 10 \mathrm{H}_{2} \mathrm{O}$ or $\mathrm{NaOAc} \cdot 3 \mathrm{H}_{2} \mathrm{O}$ with glycerol all showed a linear increase in $T_{g}$ with increasing salt concentration, and did not show the characteristic depression, which is observed with DES, which is shown by the purple trend $(\mathrm{ChCl})$ in Figure 2. Aqueous solutions of $\mathrm{NaCl}$ are known to show a depression in melting 
temperature with a eutectic composition of $23.3 \mathrm{wt} \%$ which equates to $6.7 \mathrm{~mol} \%$ or a concentration of approximately $4 \mathrm{M}^{16}$ The $3.55 \mathrm{M} \mathrm{NaBr}$ solution in glycerol equates to 22.5 mol\% suggesting a eutectic composition might be observable at much lower salt concentrations but because true melting points are not observed (only $T_{g}$ ) eutectic formation may not be observable. Zaidi et al. developed an electrolyte based on sodium nitrate and Nmethylacetamide and found a 1:9 respective molar ratio lead to a system with a melting point below that of the components, suggesting eutectic systems are possible with sodium salts, and an alternative method of determining melting points may be necessary. ${ }^{17}$

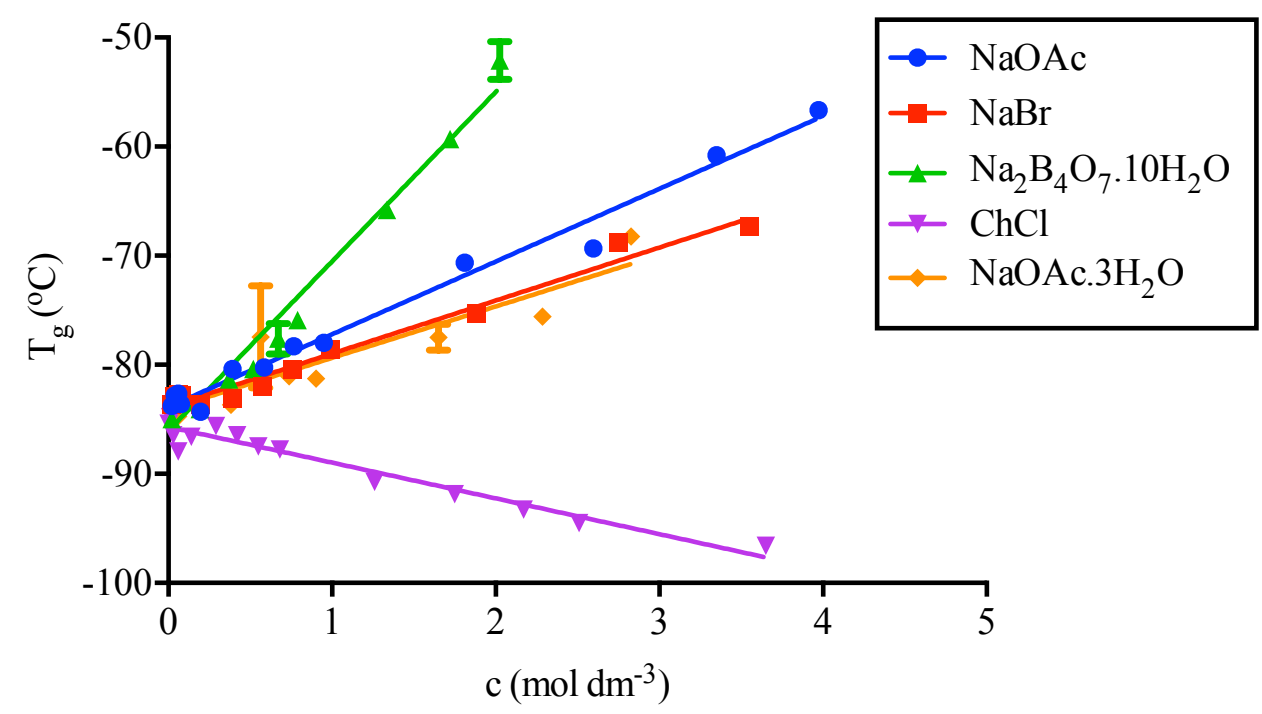

Figure 2. Glass transition onset temperature for a series of salt: glycerol mixture as a function of salt concentration with linear trend lines.

The positive trends in $T_{g}$ in Figure 2 suggest the inorganic salts tested have a reinforcing effect (kosmotropic) on the structure of glycerol as the heat energy required to transfer into the molten state increases with salt concentration. In contrast, the quaternary ammonium salt, QASs used in DESs appear to have a structure disrupting (chaotropic) effect on glycerol as the heat energy required to transfer into the molten state decreases with salt concentration until the eutectic point. At low QAS concentrations, the $T_{g}$ of glycerol appears to initially increase, which is surprising as a linear response is observed for the inorganic salts studied. The $[\mathrm{EMIM}] \mathrm{Cl} / \mathrm{AlCl}_{3}$ system shows a eutectic maximum at an approximate $\mathrm{AlCl}_{3}$ mole fraction of 0.5 , due to the presence of different anionic species at different molar ratios of [EMIM]Cl to $\mathrm{AlCl}_{3}$. ${ }^{18,19}$ 


\section{Viscosity}

Figure 3 shows the viscosity of the salt: glycerol mixture as a function of salt concentration. At the highest concentrations measured for each sodium salt: glycerol system, viscosity varied from $487 \pm 3 \mathrm{cP}$ for a $2.83 \mathrm{M} \mathrm{NaOAc} \cdot 3 \mathrm{H}_{2} \mathrm{O}$ mixture to $16300 \pm 100 \mathrm{cP}$ for a $3.98 \mathrm{M}$ $\mathrm{NaOAc}$ mixture at $298 \mathrm{~K}$. The range of viscosities measured is comparable with what is typically seen with DESs but are considerably more viscous that most commonly used ILs and molecular solvents. ${ }^{15}$

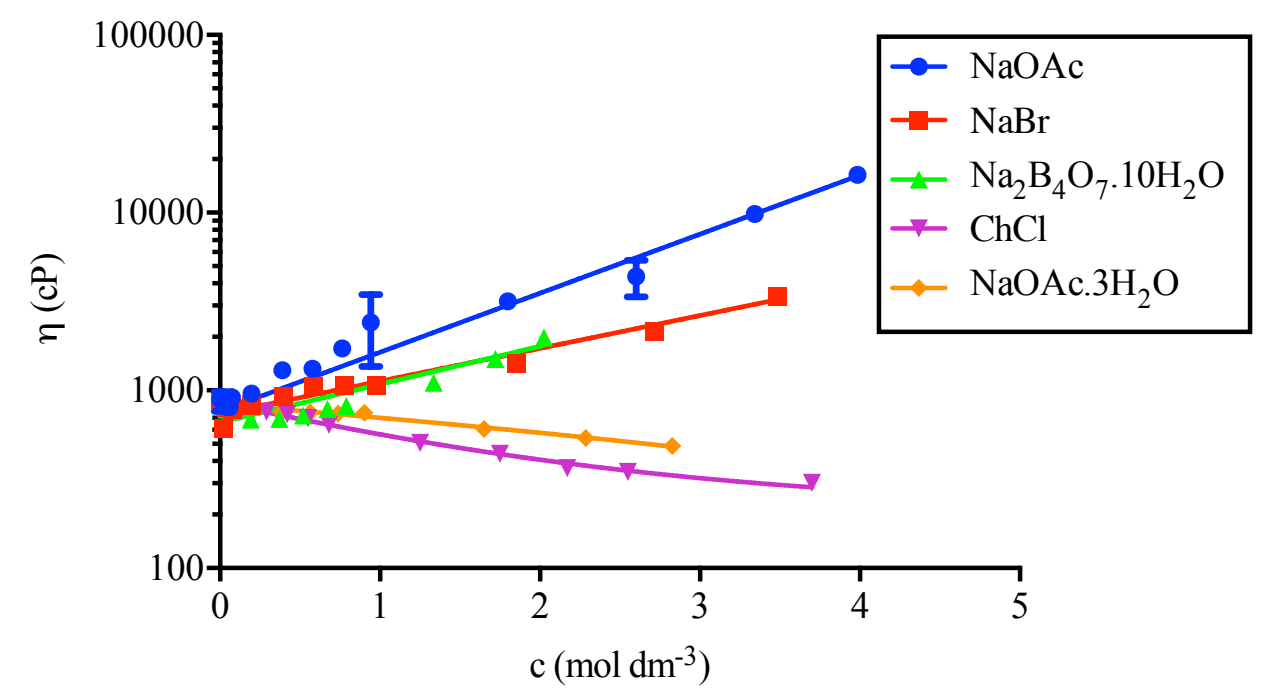

Figure 3. Viscosity measurements for a series of salt: glycerol mixture as a function of salt concentration at $298 \mathrm{~K}$ with linear trend lines.

Except for $\mathrm{NaOAc} \cdot 3 \mathrm{H}_{2} \mathrm{O}$, the other sodium salts studied, at all concentrations, increased the viscosity of glycerol. Ionic species that have high charge densities are known to have a kosmotropic effect on polar solvents resulting in stronger solvent-solvent interactions. ${ }^{20,21}$ In the context of viscosity, stronger solvent-solvent interactions implies greater resistive forces between shear planes, which results in a greater $E_{\eta}$ that leads to a greater dynamic viscosity. Not all inorganic salts have a structure forming effect on the viscosity of water, and the observed effect is dependent on the components of the salt. ${ }^{22}$ (See supplementary data file for a full Dole-Jones analysis of the data)

It has previously been shown that QASs decrease the viscosity of glycerol, oxalic acid, urea and other HBD as a function of QAS concentration. ${ }^{23,24}$, This was rationalised as the QAS disrupts the hydrogen bonding network and decreases the viscosity due to weaker resistive forces between fluid shear planes, which lower $E_{\eta} .{ }^{23}$ Chaotropic salts are known to show structure breaking effects via disruption of non-covalent intermolecular forces. This can 
result in the formation of ion-dipole interactions between ions and the hydrogen-bonding species, which is thermodynamically favourable compared to the solvent intermolecular interactions. $^{25}$

The role of water is not clear from the trends shown in Figure 3 as $\mathrm{NaOAc} \cdot 3 \mathrm{H}_{2} \mathrm{O}$ shows a decrease in viscosity as a function of salt concentration, whereas $\mathrm{Na}_{2} \mathrm{~B}_{4} \mathrm{O}_{7} \cdot 10 \mathrm{H}_{2} \mathrm{O}$ indicates in increase in viscosity. A comparison between $\mathrm{NaOAc} \cdot 3 \mathrm{H}_{2} \mathrm{O}$ and $\mathrm{NaOAc}$ suggests the waters of hydration may be relatively free, implying the free water could act as a diluent. Unfortunately, a comparison between $\mathrm{Na}_{2} \mathrm{~B}_{4} \mathrm{O}_{7} \cdot 10 \mathrm{H}_{2} \mathrm{O}$ and $\mathrm{Na}_{2} \mathrm{~B}_{4} \mathrm{O}_{7}$ could not be achieved, as $\mathrm{Na}_{2} \mathrm{~B}_{4} \mathrm{O}_{7}$ is insoluble in glycerol.

There are conflicting arguments in the literature regarding the fluid behaviour of ILs and DESs, but component choice has been repeatedly regarded as the deciding factor. ${ }^{26,27}$ The viscosity of approximately $2 \mathrm{M}$ salt: glycerol mixtures were studied as a function of viscometer rotation speed. The $\mathrm{NaBr}, \mathrm{Na}_{2} \mathrm{~B}_{4} \mathrm{O}_{7} \cdot 10 \mathrm{H}_{2} \mathrm{O}, \mathrm{ChCl}, \mathrm{NaOAc} \cdot 3 \mathrm{H}_{2} \mathrm{O}$ systems and pure glycerol showed a Newtonian fluid response. The NaOAc system showed a positive gradient, which suggests the $\mathrm{NaOAc}$ : glycerol system is behaving as a shear-thickening fluid. (See supplementary data file) Shear-thickening fluid behaviour is typical of many colloidal suspensions, and is a result of a system crystallising under stress and behaving more like a solid. ${ }^{28}$ ILs generally show shear thinning fluid characteristics at high shear rates, which has been attributed to the onset of stacking of polar and apolar layers that breaks down the hydrogen-bonded network, thus accommodating easier shear deformation. ${ }^{29}$ Jacquemin et al. found diisopropyl-ethylammonium based protic ionic liquids showed shear-thickening behaviour at shear rates greater than $4000 \mathrm{~s}^{-1}$; however, they gave no indication as to why the phenomenon occurred. ${ }^{30}$ Abbott et al. found that the eutectic mixture of $\mathrm{ChCl}$ and urea showed non-Newtonian fluid properties in the pure state. Upon the addition of $2.5 \%$ water, the mixture was found to behave as a Newtonian fluid. ${ }^{13}$ The pronounced effect of water on the fluid behaviour of the $\mathrm{ChCl}$ : urea mixture was linked to the hydrogen bond donating parameter $(\alpha)$ of the system being lower compared to other $\mathrm{ChCl}$ : $\mathrm{HBD}$ systems and pure water, which suggested water was preferentially solvating the chloride anion. Studies into the solvent parameters of sodium salt: glycerol mixtures have not been investigated, and studies in this area may be needed to explain the uncharacteristic fluid behaviour in the NaOAc: glycerol system. 


\section{Ionic Conductivity}

Figure 4 shows the change in molar conductivity ( 1$)$ as a function of the square root of salt concentration for a series of salt: glycerol systems. $\mathrm{ChCl}$ : glycerol mixtures show a decrease in molar conductivity up to $0.25 \mathrm{M}$ suggesting the formation of ion pairs, followed by an increase to approximately $4 \mathrm{M}$, which is indicative of triple ion formation. Concentrations larger than $4 \mathrm{M}$ cause a decrease in molar conductivity due to decreased ionic mobility. ${ }^{31}$ $\mathrm{NaOAc}$ and $\mathrm{NaBr}$ mixtures with glycerol show a consistent decrease in molar conductivity across the measured concentration range, which appears to be due to the high viscosity of the liquids. ${ }^{32}$.

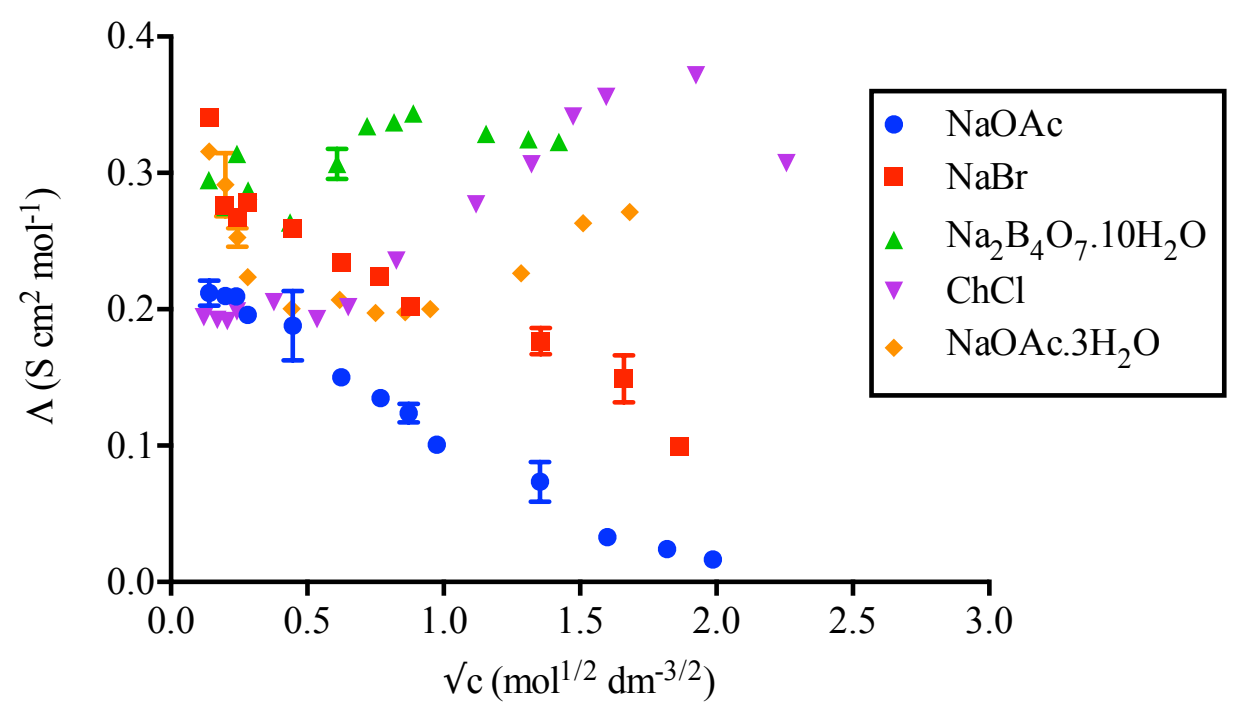

Figure 4. Molar conductivity measurements for a series of salt: glycerol mixtures as a function of the square root of salt concentration at $298 \mathrm{~K}$.

The $\mathrm{NaOAc} \cdot 3 \mathrm{H}_{2} \mathrm{O}$ : glycerol system shows an initial decrease in molar conductivity followed by an increase above $0.25 \mathrm{M}$. This behaviour is usually characteristic of ion pair formation at lower concentrations followed by triple ion formation beyond the minimum. The trend displayed by the $\mathrm{NaOAc} \cdot 3 \mathrm{H}_{2} \mathrm{O}$ : glycerol system is very different to that of the anhydrous system and suggests water is contributing to the charge transport mechanisms in this system. Water may help to solvate the sodium ions enabling more charge separation and showing a contribution from ion aggregates (e.g. triple ions) rather than molar conductivity being controlled just by ion transport. The $\mathrm{Na}_{2} \mathrm{~B}_{4} \mathrm{O}_{7} \cdot 10 \mathrm{H}_{2} \mathrm{O}$ :glycerol system does not show a clear trend in Figure 4, but molar conductivity is in the range 0.27 to $0.34 \mathrm{~S} \mathrm{~cm}^{2} \mathrm{~mol}^{-1}$ implying little variance occurs. It suggests that water may be behaving differently than in $\mathrm{Na}_{2} \mathrm{~B}_{4} \mathrm{O}_{7} \cdot 10 \mathrm{H}_{2} \mathrm{O}$ : glycerol compared to the $\mathrm{NaOAc} \cdot 3 \mathrm{H}_{2} \mathrm{O}$ : glycerol system. It has previously 
been shown that addition of $5 \mathrm{wt} \%$ water to a range of $\mathrm{ChCl}$ : $\mathrm{HBD}$ systems significantly decreased viscosity and in turn increased molar conductivity. ${ }^{13}$ At $0.08 \mathrm{M}, \mathrm{Na}_{2} \mathrm{~B}_{4} \mathrm{O}_{7} \cdot 10 \mathrm{H}_{2} \mathrm{O}$ in glycerol the water content of the system is $5.5 \mathrm{wt} \%$, and at $2.02 \mathrm{M}$, the water content is $69.2 \%$. Despite the significant water contents, little variance in molar conductivity occurs, which suggests some of the waters of hydration are bound sto the sodium cation and the tetraborate anion. The anion can be more precisely written as $\left[\mathrm{B}_{4} \mathrm{O}_{5}(\mathrm{OH})_{4}\right]^{2-}$ showing that two of the water molecules are covalently bound to the anion.

At their maximum concentrations, the sodium salt: glycerol systems showed molar conductivities in the range 0.02 to $0.32 \mathrm{~S} \mathrm{~cm}^{2} \mathrm{~mol}^{-1}$, whereas ILs are typically in the 0.35 to $10 \mathrm{~S} \mathrm{~cm}^{2} \mathrm{~mol}^{-1}$ range, and DESs are 0.05 to $3 \mathrm{~S} \mathrm{~cm}^{2} \mathrm{~mol}^{-1}$.,15 The sodium salt: glycerol systems measured are significantly lower than those generally experienced for ILs however, ILs are normally less viscous than the sodium salt: glycerol mixtures and DESs allow for a much greater ion mobility. ${ }^{15}$

Figure 5 shows the logarithmic plots of molar conductivity vs. fluidity for a series of approximately $2 \mathrm{M}$ sodium salt: glycerol systems as a function of temperature. Molar conductivity has been substituted for molal conductivity to provide an absolute concentration factor that did not vary with temperature. In all instances, there is a clear linear trend between molal conductivity and fluidity. The slopes of these lines, known in the literature as Walden products (molar conductivity $\times$ viscosity) are summarised in Table $\mathbf{1}$.

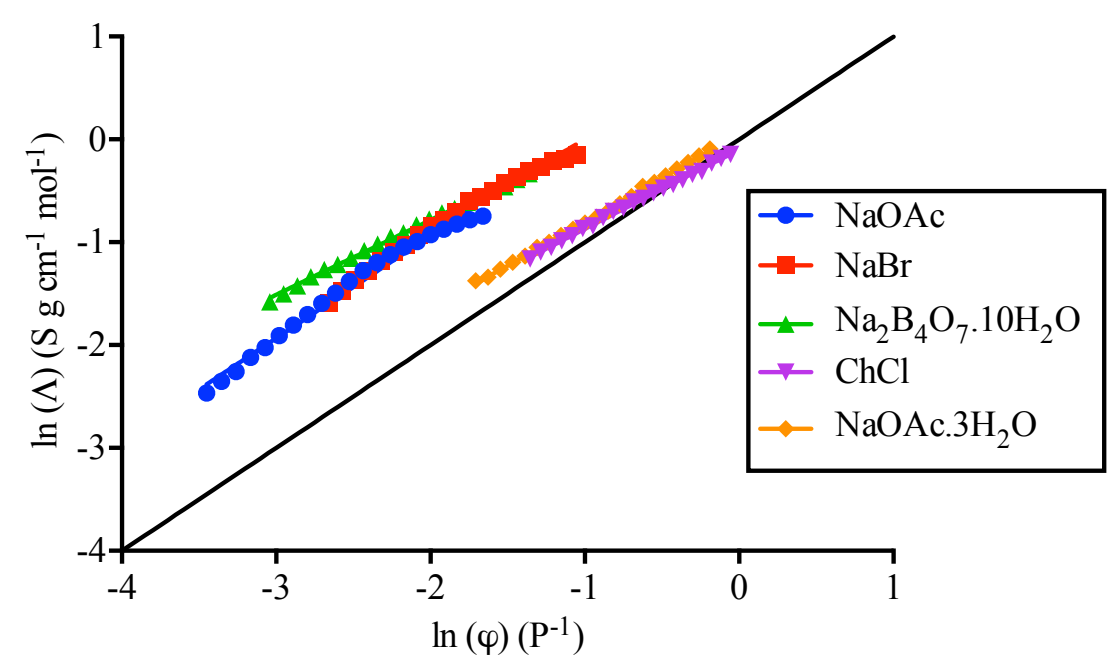

Figure 5. Walden plots for a series of approximately $2 M$ salt: glycerol mixtures as a function of temperature. 
The Walden product describes the effect of fluidity on molar conductivity. The $\mathrm{NaOAc}, \mathrm{NaBr}$ and $\mathrm{Na}_{2} \mathrm{~B}_{4} \mathrm{O}_{7} \cdot 10 \mathrm{H}_{2} \mathrm{O}$ systems all show very similar, comparatively high, Walden products showing that fluidity has a significant effect on conductivity. Systems where the molar conductivity lies above the black equivalence line ( $\mathrm{NaOAc}, \mathrm{NaBr}$ and $\mathrm{Na}_{2} \mathrm{~B}_{4} \mathrm{O}_{7} \cdot 10 \mathrm{H}_{2} \mathrm{O}$ in Figure 5) are generally described as superionic glasses.

Table 1. Walden products of salts in glycerol.

\begin{tabular}{cc}
\hline Salt: glycerol system & Walden product $\left(\mathbf{S ~ g ~ c m}^{-\mathbf{1}} \mathbf{~ m o l}^{-1} \mathbf{P}\right)$ \\
\hline $\mathrm{NaOAc}$ & $2.63 \pm 0.10$ \\
\hline $\mathrm{NaBr}$ & $2.45 \pm 0.08$ \\
\hline $\mathrm{Na}_{2} \mathrm{~B}_{4} \mathrm{O}_{7} \cdot 10 \mathrm{H}_{2} \mathrm{O}$ & $2.42 \pm 0.05$ \\
\hline $\mathrm{ChCl}$ & $0.79 \pm 0.01$ \\
\hline $\mathrm{NaOAc} \cdot 3 \mathrm{H}_{2} \mathrm{O}$ & $1.02 \pm 0.01$ \\
\hline
\end{tabular}

ILs typically have Walden products in the range $0.30-1.00 \mathrm{~S} \mathrm{~cm}^{2} \mathrm{~mol}^{-1} \mathrm{P}^{15}$ The $\mathrm{NaOAc} \cdot 3 \mathrm{H}_{2} \mathrm{O}$ and the $\mathrm{ChCl}$ systems both show lower Walden constants. This could be because the first three liquids exhibit greater structure compared to the other two. This certainly fits with the data in Figure 3 and confirms that the latter two are structure breaking. For both $\mathrm{NaBr}$ and $\mathrm{NaOAc}$ the salt decreases the free volume of the liquid which in turn increases the viscosity and $\mathrm{Tg}$ and results in low molar conductivities which would be expected for structure making salts (see supplementary data file). The hydrate salts, however behave differently. $\mathrm{NaOAc} .3 \mathrm{H}_{2} \mathrm{O}$ shows a decrease in free volume accompanied by a decrease in viscosity whereas $\mathrm{Na}_{2} \mathrm{~B}_{4} \mathrm{O}_{7} \cdot 10 \mathrm{H}_{2} \mathrm{O}$ shows an increase in free volume but an increase in viscosity. This must be due to the behaviour of the hydrate water molecules. To probe this further diffusional measurements were carried out to understand the mobilities of the individual species.

\section{${ }^{1}$ H PFG NMR measurements}

A typical PFG NMR signal decay measured for the samples studied in this work is shown in Figure 6A, which shows the diffusion attenuation of NaOAc sample at $298.15 \mathrm{~K}$. It is possible to observe the signal attenuation of the NMR resonances of the different species, in particular the hydroxyl and aliphatic resonance of glycerol at $4.54 \mathrm{ppm}$ and $2.68 \mathrm{ppm}$, respectively, and the resonance of the $\mathrm{OAc}^{-}$anion at $1.03 \mathrm{ppm}$. The figure also shows the usefulness and potential of this technique, which is able probe multi-component diffusion 
even in cases of such samples, whereby the NMR resonances are broadened due to the significant high values of viscosity. ${ }^{13}$

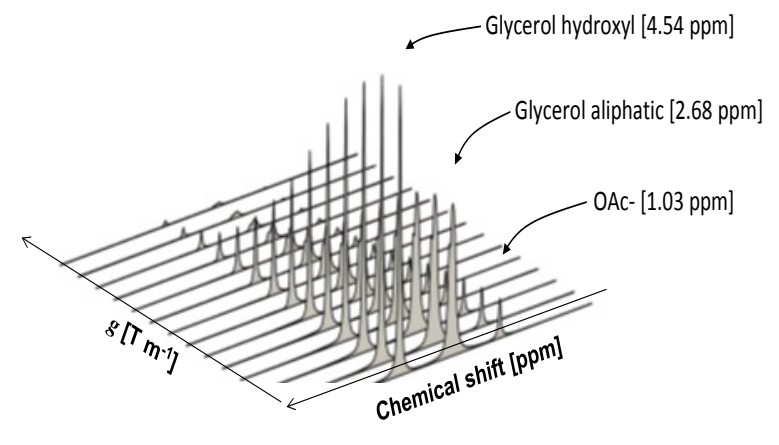

A

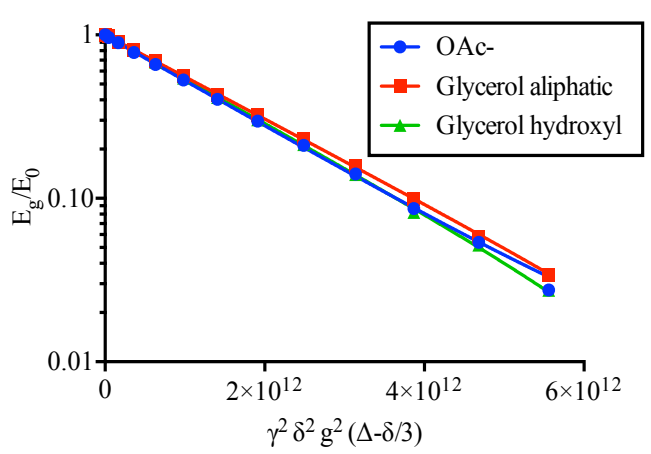

B

Figure 6. Typical NMR spectrum of the NaOAc: glycerol system (A) and associated characteristic signal decay profile (B).

From the plot in Figure 6B it is possible to obtain the Stejkal-Tanner plot, ${ }^{33}$ i.e., $E(g) / E_{0}$ vs. $\gamma_{H}^{2} g^{2} \delta^{2}(\Delta-\delta / 3)$, which is then used to extrapolate the value of self-diffusion coefficient by taking the negative of the slope of this plot. As an example of such plots, Figure 6B shows the log attenuation plots the glycerol and acetate resonances of the NaOAc. The reproducibility of the measurements had a relative error of approximately $3 \%$.

A summary of the diffusion measurements at variable temperature is shown in Figure 7 in terms of self-diffusion coefficients plotted against 1000/T. Figures 7A and B show the selfdiffusion coefficient for the NaOAc: glycerol and $\mathrm{NaBr}$ : glycerol systems. In both cases there is relatively good agreement between the measured self-diffusion coefficients and that calculated by the Stokes Einstein equation. The $\mathrm{Na}_{2} \mathrm{~B}_{4} \mathrm{O}_{7} \cdot 10 \mathrm{H}_{2} \mathrm{O}$ : glycerol and $\mathrm{NaOAc} \cdot 3 \mathrm{H}_{2} \mathrm{O}$ : systems in Figures 7C and 7D, shows poor agreement for both the glycerol hydroxyl protons which are in some cases underestimated by an order of magnitude. This suggest water plays a significant role in delocalising the hydroxyl protons whilst having only a nominal effect on the aliphatic parent molecule, which agrees with the uncharacteristically high diffusivity of the hydroxyl protons in such a viscous medium. This suggests the aliphatic glycerol parent species and the acetate anion are more mobile in the $\mathrm{NaOAc} \cdot 3 \mathrm{H}_{2} \mathrm{O}$ system, compared to the aliphatic glycerol parent species and the tetraborate anion in the $\mathrm{Na}_{2} \mathrm{~B}_{4} \mathrm{O}_{7} \cdot 10 \mathrm{H}_{2} \mathrm{O}$ system, hence the lower observed macroscopic viscosity. The diffusivity of the hydrate waters is more restricted than would be expected from a pure water phase, showing that the system is quite complex and not just two separate phases. 
NMR diffusion measurements show a single average diffusion coefficient that describes the hydroxyl proton of glycerol and water protons, suggesting an exchange of protons between the two species diffusing at that average rate. Such phenomena have previously been observed when studying diffusion in alcohol/water solutions. ${ }^{34}$ This also implies that glycerol hydroxyls are diffusing in a rather "independent" fashion relative to their aliphatic parent molecules, which agrees with previous observation on aqueous DES samples. ${ }^{13}$ Otherwise, the NMR signal decay for the glycerol $\mathrm{OH} /$ water peak would clearly show a much slower second component with values of close to the self-diffusivity of the glycerol aliphatic chain, which is not the case.

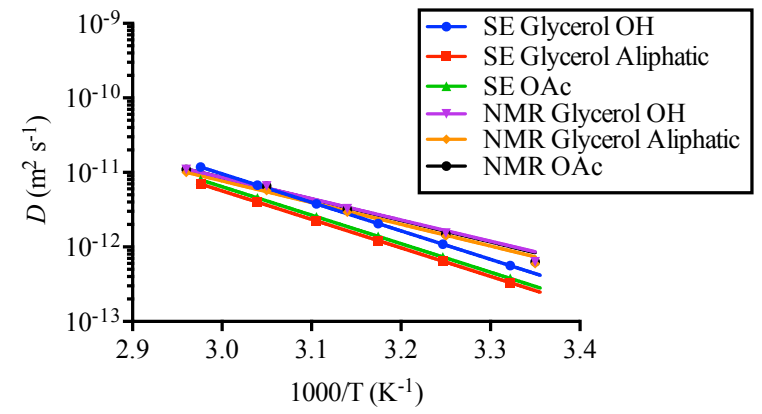

A) $\mathrm{NaOAc}$

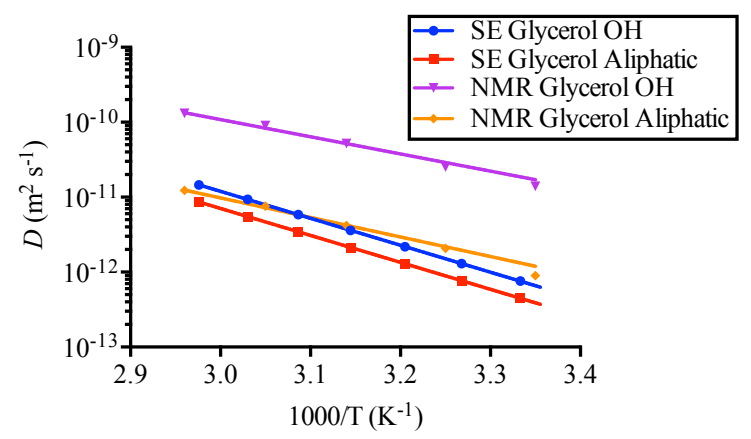

C) $\mathrm{Na}_{2} \mathrm{~B}_{4} \mathrm{O}_{7} \cdot 10 \mathrm{H}_{2} \mathrm{O}$

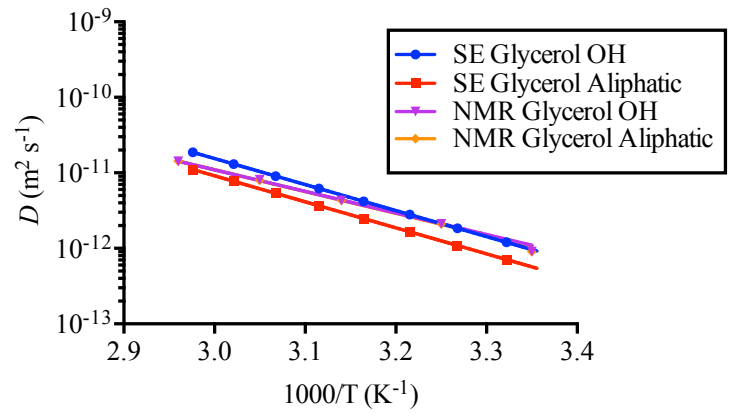

B) $\mathrm{NaBr}$

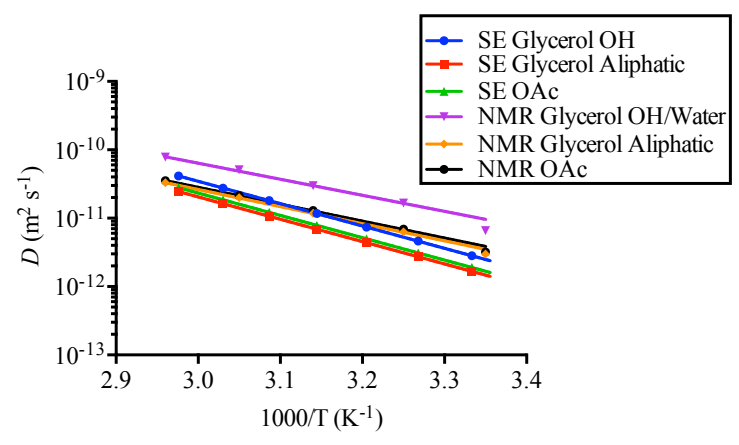

D) $\mathrm{NaOAc} \cdot 3 \mathrm{H}_{2} \mathrm{O}$

Figure 7. Self-diffusion coefficients measured by NMR and calculated using Stokes-Einstein (SE) versus inverse temperature for a range of salt: glycerol mixtures. Within each plot there are trends from PFG NMR and trends from the Stokes-Einstein equation.

The above observations agree with the molar ionic conductivity behaviour reported in Figure 4, as the NaOAc: glycerol has the lowest molar ionic conductivity and $\mathrm{Na}_{2} \mathrm{~B}_{4} \mathrm{O}_{7} \cdot 10 \mathrm{H}_{2} \mathrm{O}$ : the 
highest. This suggests that free hydroxyl protons may be involved in the charge transport mechanism as the molar ionic conductivities of the sodium salt: glycerol systems appear to be dependent on the mobility of the glycerol hydroxyl protons. The relatively free nature of the hydrate waters in the $\mathrm{Na}_{2} \mathrm{~B}_{4} \mathrm{O}_{7} \cdot 10 \mathrm{H}_{2} \mathrm{O}$ : glycerol system may explain why the free volume of this system increases with salt concentration, whereas the free volume of the $\mathrm{NaOAc} \cdot 3 \mathrm{H}_{2} \mathrm{O}$ glycerol system decreases with salt concentration. (See supplementary data file)

The diffusion data as a function of temperature were fitted with an Arrhenius expression $D(T)=D_{0} \exp \left(-E_{a} / R T\right)$ and plotted on a vertical log scale, from which it is possible to calculate the activation energy barrier for diffusion, $E_{a}$. The values of activation energy for diffusion are reported in Table 2:

Table 2. Activation energies of NMR self-diffusivity.

\begin{tabular}{ccccc}
\cline { 2 - 5 } Sample & Glycerol $\mathbf{~ O H}$ & $\begin{array}{c}\text { Glycerol } \\
\text { OH/ Water }\end{array}$ & $\begin{array}{c}\text { Glycerol } \\
\text { aliphatic H }\end{array}$ & Acetate aliphatic H \\
\hline $\mathrm{NaOAc}$ & $53.4 \pm 2.9$ & - & $54.5 \pm 1.7$ & $53.9 \pm 2.9$ \\
\hline $\mathrm{NaBr}$ & $53.4 \pm 1.2$ & - & $54.0 \pm 0.9$ & - \\
\hline $\mathrm{Na}_{2} \mathrm{~B}_{4} \mathrm{O}_{7} \cdot 10 \mathrm{H}_{2} \mathrm{O}$ & - & $42.9 \pm 3.0$ & $48.8 \pm 2.1$ & - \\
\hline $\mathrm{NaOAc}_{3} \mathrm{H}_{2} \mathrm{O}$ & - & $44.9 \pm 2.5$ & $47.9 \pm 0.9$ & $47.3 \pm 1.1$ \\
\hline
\end{tabular}

The $E_{a}$ values are similar to those for other ionic liquids ${ }^{23}$ but Table 2 shows that the presence of water decreases $E_{a}$ for diffusion which can be seen by comparing the dry and hydrate NaOAc samples. $E_{a}$ for the glycerol hydroxyl/water protons in exchange are significantly lower than those measured for the glycerol hydroxyl diffusion only.

In terms of relating the viscosity of the sample with the experimental NMR diffusion coefficients, it is clear that in general the samples with lower self-diffusion coefficient of the various ${ }^{1} \mathrm{H}$ different species are those with the highest viscosity. However, the mobility of the ${ }^{1} \mathrm{H}$ species is not sufficient to fully explain the viscosity data. Indeed, comparison of the $\mathrm{NaBr}$ data in Figure $7 \mathrm{~B}$ with sample $\mathrm{Na}_{2} \mathrm{~B}_{4} \mathrm{O}_{7} \cdot 10 \mathrm{H}_{2} \mathrm{O}$, might lead to the conclusion that the latter should be less viscous. Both samples have similar diffusivity values for the glycerol aliphatic chain; the latter, however, shows an increased mobility of the glycerol hydroxyl protons in 
exchange with water despite $\mathrm{Na}_{2} \mathrm{~B}_{4} \mathrm{O}_{7} \cdot \mathrm{H}_{2} \mathrm{O}$ having a higher viscosity. This suggests that the $\mathrm{Na}_{2} \mathrm{~B}_{4} \mathrm{O}_{7}$ plays a crucial role in increasing the viscosity of this sample due to solution ordering.

Measurements of diffusion coefficients for $\mathrm{Na}^{+}$ions in these samples were not possible due to the very high solution viscosity; this, together with the quadrupolar interaction involved in ${ }^{23} \mathrm{Na}$ NMR makes the relaxation times of these species extremely short precluding PFG NMR measurements even by minimising the echo time in the pulse sequence. Indeed, we measured $T_{1}$ values for these samples of the order of $\mu \mathrm{s}$, which are extremely small. Given that the $T_{2}$ transverse relaxation is equal or less then $T_{1},{ }^{35}$ no ${ }^{23} \mathrm{Na}$ NMR signal could be detected.

To circumvent this problem, $T_{1}$ relaxation measurements were carried out on both ${ }^{1} \mathrm{H}$ and ${ }^{23} \mathrm{Na}$ to give useful information on rotational dynamics ${ }^{36}$ and gain further information on the microscopic behaviour.

\section{${ }^{1} \mathrm{H}$ and ${ }^{23} \mathrm{Na}$ NMR $T_{1}$ relaxation measurements}

The ${ }^{1} \mathrm{H} T_{1}$ relaxation times for the proton species in the different samples as a function of temperature are reported in Figure 8. Minima in the $T_{1}$ relaxation times can be observed in many cases, which has been previously observed by Remsing et al. ${ }^{37}$ and Hayamizu et al. ${ }^{36}$ when studying ionic liquids with similar viscosities and diffusivities to those reported in this work.

For non-viscous liquids, $T_{1}$ usually increases with temperature, i.e., $T_{1}$ increases with temperature as the rotational correlation time decreases due to a faster molecular tumbling rate. ${ }^{35}$ However, for very viscous samples, minima in $T_{1}$ can be observed, as a result of the Bloembergen-Purcell-Pound (BPP) theory of liquid relaxation. ${ }^{38}$ The presence of minima indicates a transition from the slow tumbling (or diffusion limit) relaxation regime, where $\omega_{0} \tau>1$ to the fast tumbling (or extreme narrowing) relaxation regime, where $\omega_{0} \tau<1$. Here $\omega_{0}$ is the frequency and $\tau$ is the correlation time for molecular tumbling. ${ }^{35}$ As the temperature increases a transition from diffusion limit regime (low mobility, higher correlation times) to extreme narrowing (fast mobility, lower correlation times) occurs. 


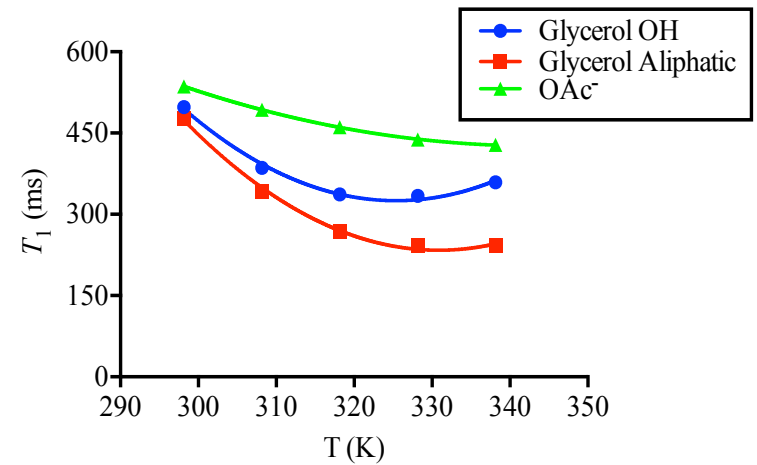

A) $\mathrm{NaOAc}$

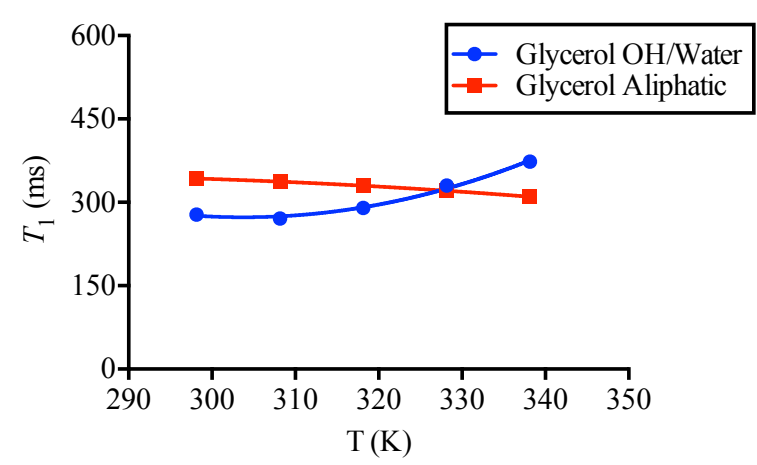

C) $\mathrm{Na}_{2} \mathrm{~B}_{4} \mathrm{O}_{7} \cdot 10 \mathrm{H}_{2} \mathrm{O}$

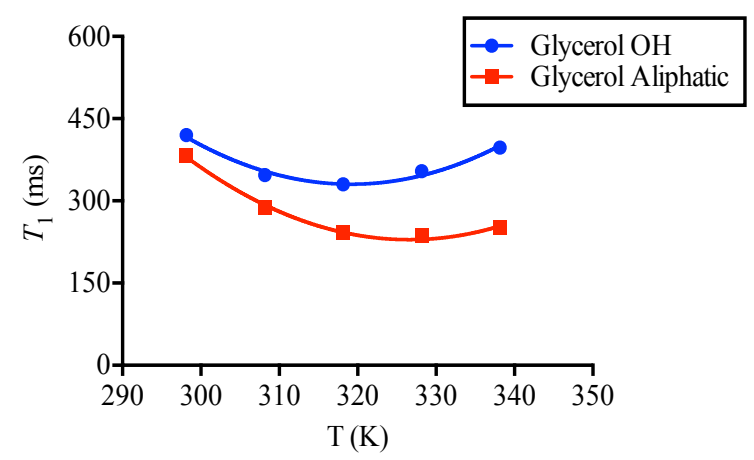

B) $\mathrm{NaBr}$

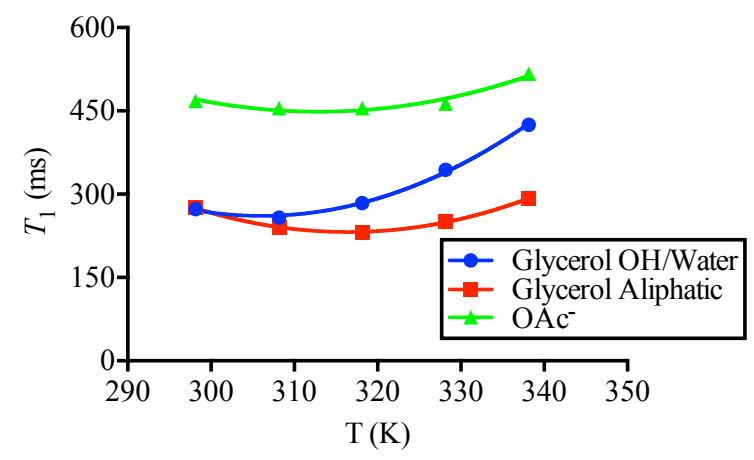

D) $\mathrm{NaOAc} \cdot 3 \mathrm{H}_{2} \mathrm{O}$

Figure 8. ${ }^{1} H T_{1}$ relaxation times versus temperature for a range of salt: glycerol mixtures. Changes in $T_{1}$ relaxation times as a function of temperature are linked to changes in molecular dynamics.

Analysis of the $T_{1}$ trends using the BPP theory shows that the faster the mobility of the species under investigation, the lower the temperature at which this transition from slow to fast regime occurs, in other words, more mobile species will be in the fast regime at lower temperatures. ${ }^{35}$

In $\mathrm{NaOAc}$, Figure 8A, this transition occurs above $328 \mathrm{~K}$ for the glycerol $\mathrm{OH}$, whereas it is not observed at all for the glycerol aliphatic and the acetate anion, which both remain in the slow tumbling regime. This is consistent with the much higher viscosity and lower mobility of these species compared to the mobility in $\mathrm{NaBr}$, Figure 8B. It is noted that $\mathrm{NaOAc}$ is the sample with the highest viscosity among the sample studied here. For $\mathrm{NaBr}$ this transition occurs at about $318 \mathrm{~K}$ for the glycerol $\mathrm{OH}$ and at $325 \mathrm{~K}$ for the glycerol aliphatic, which is reasonable as in general we expect the hydroxyls to be more mobile than the aliphatic chains. 
In Figure 8D the $\mathrm{NaOAc} \cdot 3 \mathrm{H}_{2} \mathrm{O}$, has the highest mobility (lowest viscosity) and highest diffusivity values of all species with the transition for the glycerol $\mathrm{OH} /$ water occurring at 308 $\mathrm{K}$ and that for the glycerol aliphatic, at about $315 \mathrm{~K}$ which is consistent with the other results. In $\mathrm{Na}_{2} \mathrm{~B}_{4} \mathrm{O}_{7} \cdot \mathrm{H}_{2} \mathrm{O}$, Figure $\mathbf{8 C}$, the transition for the glycerol $\mathrm{OH} /$ water peak is observed at about $308 \mathrm{~K}$, a value lower than the minimum for the glycerol $\mathrm{OH}$ observed in $\mathrm{NaBr}$, which is consistent with the higher mobility of these protons in exchange with water as measured by PFG NMR. However, the glycerol aliphatic fails to undergo this transition and remains in the slow tumbling regime. This may therefore explain the observation that, despite the presence of mobile water, overall, this sample has a viscosity significantly higher than that of $\mathrm{NaBr}$. In addition, it is noted that the diffusivity values of the glycerol aliphatic in $\mathrm{Na}_{2} \mathrm{~B}_{4} \mathrm{O}_{7} \cdot \mathrm{H}_{2} \mathrm{O}+$ glycerol are lower than those observed in $\mathrm{NaBr}$, which is consistent with the restricted mobility.

In order to have further insight into the molecular dynamics in these samples, ${ }^{23} \mathrm{Na}$ NMR $T_{1}$ relaxation time measurements have also been carried out to probe the behaviour of the $\mathrm{Na}^{+}$ ions and see how this correlates with the viscous properties of these liquids. Compared to ${ }^{1} \mathrm{H}$ NMR, ${ }^{23} \mathrm{Na}$ NMR spectra are very broad due to the very high viscosity and quadrupolar interactions in the liquids. ${ }^{39}$ The results are shown in Figure 9. The ${ }^{23} \mathrm{Na} T_{1}$ relaxation times are much shorter than the ${ }^{1} \mathrm{H} T_{1}$ values of the other species due to ${ }^{23} \mathrm{Na}$ being quadrupolar with enhanced relaxation. ${ }^{39}$ The analysis of these relaxation times can also be carried out using the BPP theory approach for liquids as it has previously been done for other quadrupolar species. $^{37}$ 


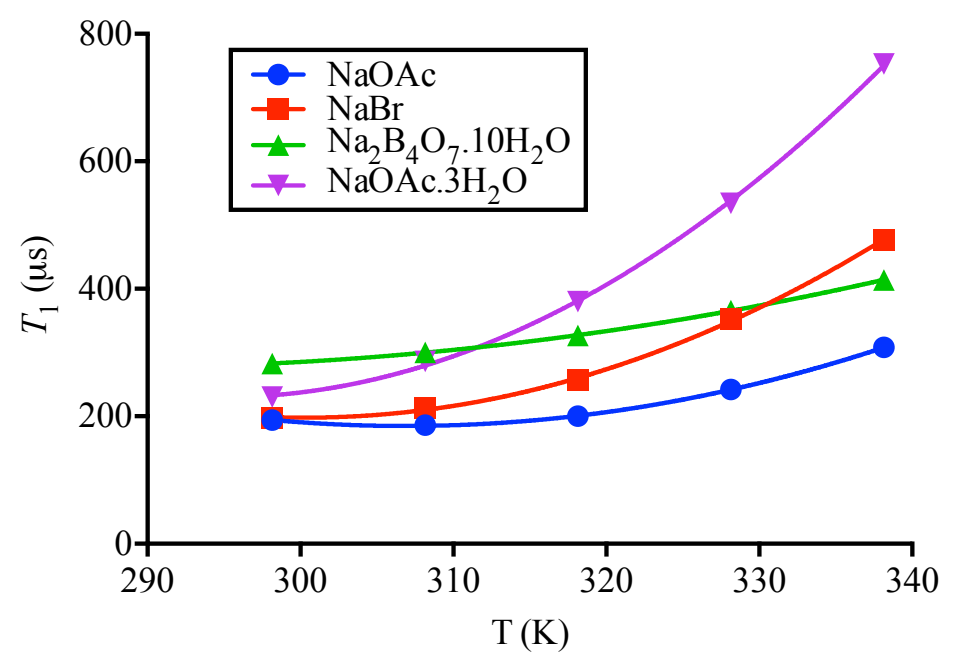

Figure 9. $T_{1}$ relaxation times ${ }^{23} \mathrm{Na}$ versus temperature for a range of salt: glycerol mixtures with non-linear trend lines. The results show that Na ions have a significantly different molecular dynamics in the different salts.

The NaOAc sample, Figure 9, is the only one showing a minimum for the ${ }^{23} \mathrm{Na} T_{1}$ in the range of temperature studied, which implies a transition from the slow to fast regime. In all the other samples, the value of $T_{1}$ increases with temperature in all cases. This implies that at those temperatures we are already in the fast regime for these samples as opposed to the case of $\mathrm{NaOAc}$, which ties in with the much higher viscosity of this sample compared with the other ionic liquids.

Compared to the trend observed for ${ }^{1} \mathrm{H} T_{1}$ relaxation times, we can see a much steeper rise of the ${ }^{23} \mathrm{Na} T_{1}$ values with temperature. This pronounced increase correlates well with the changes in viscosity observed and indicates a weakening of inter-ionic interactions. ${ }^{37}$ The rather different trend of ${ }^{23} \mathrm{Na} T_{1}$ as a function of temperature compared to the other ${ }^{1} \mathrm{H}$ species also suggests that the dynamic of these ions is independent to a large extent from that of the other species. Indeed, unlike the ${ }^{1} \mathrm{H}$ species, for all the samples we can see a fully developed trend in the fast tumbling regime for ${ }^{23} \mathrm{Na} T_{1}$ times and we note that the trend for the absolute values of ${ }^{23} \mathrm{Na} T_{1}$ in the high temperature range, i.e., fast narrowing, reflects well that of viscosity: the less viscous the sample, the higher the $T_{1}$ relaxation time values (i.e., slower $1 / T_{1}$ relaxation rate), which is in agreement with the BPP theory. We can also see that the addition of water to NaOAc has a significant impact on the $T_{1}$ behaviour. When water is added the increase in ${ }^{23} \mathrm{Na} T_{1}$ become much faster and reaches much higher values, which implies an enhanced molecular dynamics in agreement with the dramatic decrease of viscosity observed. 
In summary, the macroscopic viscous properties of these liquids are determined by a series of dynamic phenomena at molecular level and the ${ }^{1} \mathrm{H}$ and ${ }^{23} \mathrm{Na}$ NMR measurements carried out in these work are able to elucidate such phenomena, which are responsible for the macroscopic behaviour of these liquids. Translational and rotational motion at microscopic level was studied using diffusion and $T_{1}$ relaxation measurements and the results correlate well with the macroscopic behaviour of these liquids. The presence of water enhances significant the molecular dynamics of the species in NaOAc. However, an unusually low viscosity for the $\mathrm{Na}_{2} \mathrm{~B}_{4} \mathrm{O}_{7} \cdot 10 \mathrm{H}_{2} \mathrm{O}$ sample is observed despite the presence of water and relatively fast translation motion of this water in fast exchange with the glycerol hydroxyl. The ${ }^{23} \mathrm{Na} N M R T_{1}$ relaxation measurements suggest that the mobility of $\mathrm{Na}_{2} \mathrm{~B}_{4} \mathrm{O}_{7}$ species play an important role in determining the macroscopic behaviour of these liquid.

\section{Conclusions}

It has been shown that concentrated mixtures can be prepared using alkali metal salts and glycerol. The mixtures are not true eutectics (the melting point does not have a minimum as a function of concentration) but they have densities, viscosities and ionic conductivities comparable to DESs and ILs. All of the systems investigated showed Newtonian fluid behaviour over the rotation rate range of the rotational viscometer used, except for the NaOAc: glycerol system where a shear thickening response was observed.

PFG NMR showed that the self-diffusion coefficients of the ions and molecules are in the range $10^{-11}-10^{-13} \mathrm{~m}^{2} \mathrm{~s}^{-1}$ which is similar to many DES and IL systems. For NaBr, the glycerol aliphatic and hydroxyl protons appear to be diffusing together, whereas in the NaOAc: glycerol system the glycerol hydroxyl protons appear to be diffusing with the acetate anion.

There appears to be a clear link between dynamic viscosity and the self-diffusivity of a species as well as between ionic conductivity and diffusion of free hydroxyl protons; however the role of water complicates the diffusion mechanism. Hydrate waters increase species self-diffusivity, and reduce the viscosity of the $\mathrm{NaOAc}^{-} 3 \mathrm{H}_{2} \mathrm{O}$ : glycerol system however, water in this system appears to be more restricted compared to the $\mathrm{Na}_{2} \mathrm{~B}_{4} \mathrm{O}_{7} \cdot 10 \mathrm{H}_{2} \mathrm{O}$ system. In all of the systems investigated, the Stokes-Einstein relationship underestimated the self-diffusion coefficients of all of the ${ }^{1} \mathrm{H}$ species probed. 
The use of ${ }^{1} \mathrm{H}$ PFG NMR diffusion measurements together with ${ }^{1} \mathrm{H}$ and ${ }^{23} \mathrm{Na} T_{1}$ relaxation measurements show that translation and rotational dynamics of ${ }^{1} \mathrm{H}$ and ${ }^{23} \mathrm{Na}$ species are intimately connected to the macroscopic behaviour of these systems in terms of ionic conductivity and viscosity.

\section{Acknowledgements}

A. P. Abbott would like to thank the Royal Society for funding the work through the Brian Mercer Award. C. D’Agostino would like to acknowledge Wolfson College, Cambridge, for supporting his research activities. S. Davis thanks EPSRC for funding a PhD studentship. 


\section{References}

1 A. P. Abbott, G. Capper, D. L. Davies and R. K. Rasheed and V. Tambyrajah, Chem. Commun., 2003, 70.

2 A. P. Abbott, D. Boothby, G. Capper, D. L. Davies and R. Rasheed, J. Am. Chem. Soc., 2004, 126, 9142.

3 E. L. Smith, A. P. Abbott and K. S. Ryder, Chem. Rev., 2014, 114, $11060-11082$

4 A. P. Abbott, J. C. Barron, K. S. Ryder and D. Wilson, Chem. Eur. J. 2007, 13, 64956501

5 H. M. A. Abood, A. P. Abbott, A. D. Ballantyne, K. S. Ryder, Chem. Commun. 2011, 47, $3523-3525$

6 A. P. Abbott, R. C. Harris, Y-T. Hsieh K. S. Ryder and I. W. Sun, Phys. Chem. Chem. Phys., 2014, 16, 14675-14681

7 M. Gambino, P. Gaune, M. Nabavian, M. Gaune-Escard, J. P. Bros, Thermochimica Acta 1987, 111, 37

8 F. S. Mjalli, J. Naser, B. Jibril, S. S. Al-Hatmi and Z. S. Gano, Thermochimica Acta, 2014, 575, 135- 143

9 F. M. Kerton, RSC Green Chemistry, Volume 2: Alternative Solvents for Green Chemistry, RSC Publishing, Cambridge, 2009, Ch. 5, 97

10 D. R. Lide, CRC Handbook of Chemistry and Physics, CRC press, Florida, $89^{\text {th }}$ Ed., 2008, Ch. 3

11 A. P. Abbott, ChemPhysChem, 2004, 5, 1242.

12 A. P. Abbott, R. C. Harris and K. S. Ryder J. Phys. Chem. B 2007, 111,4910-4914

13 C. D’Agostino, L. F. Gladden, M. D. Mantle, A. P. Abbott, E., I. Ahmed, A. Y. M. AlMurshedi and R. C. Harris, Phys. Chem. Chem. Phys., 2015, 17, 15297

14 A. Hammadi, International Journal of Thermophysics, 2004, 25, 89-111

15 P. Wasserscheid and T. Welton, Ionic Liquids in Synthesis, Wiley-VCH, Germany, 2003, Ch. 3

${ }^{16}$ B. J. J. Verbeek, MSc Thesis, Delft University of Technology

17 W. Zaidi, L. Timperman and M. Anouti, RSC Adv.,2014, 4, 45647

18 J. S. Wilkes, J. A. Levisky, R. A. Wilson and C. L. Hussey, Inorg. Chem., 1982, 21, 1263

19 A. A. Fannin, D. A. Floreani, L. A. King, J. S. Landers, B. J. Piersma, D. J. Stech, R. L. Vaughn, J. S. Wilkes and J. L. Williams, J. Phys. Chem., 1984, 88, 2614

20 S. Moelbert, B. Normand, P. De Los Rios, Biophys. Chem., 2004, 112, 45-57 
${ }^{21}$ M. P. Applebey, J. Chem. Soc., Trans., 1910, 97, 2000-2025

22 J. L. M. Poiseuille, Ann. Chim. Phys., 1847, 21, 76

23 A. P. Abbott, R. C. Harris, K. S. Ryder, C. D’Agostino, L. F. Gladden and M. D. Mantle, Green Chem., 2011, 13, 82

24 A. P. Abbott, G. Capper, D. L. Davies; H. L. Munro; R. K. Rasheed, V. Tambyrajah, Chem. Commun. 2001, 19, 2010.

25 K. D. Collins, Biophys. Journal, 1997, 72, 65-76

26 A. A. Al-Barzinjy, PhD Thesis, University of Leicester, 2015

27 J. M. Hartley, I. Chung-Man, G. C. H. Forrest, K. Singh, S. J. Gurman, K. S. Ryder, A. P. Abbott and G. Frisch, Inorg. Chem. 2014, 53, 6280-6288

28 P. C. Coleman and M. M. Painter, Fundamentals of Polymer Science: An Introductory Text, Technomic, Pennsylvania, $2^{\text {nd }}$ ed., 1997, 412-413

29 M. H. Cohen and D. Turnbull, J. Chem.Phys., 1959, 31, 1164-1169.

30 J. Jacquemin, M. Anouti and D. Lemordant, J. Chem. Eng. Data, 2011, 56, 556-564

31 A. P. Abbott and D. J. Schiffrin, J. Chem. Soc. Faraday Trans., 1990, 86, 1453-1459

32 R. M. Fuoss and C. A. Kraus, J. Am. Chem. Soc., 1957,79, 3304.

33 E. O. Stejskal and J. E. Tanner, J. Chem. Phys., 1965, 42, 288-292.

${ }^{34}$ R. Li, C. D'Agostino, J. McGregor, M. D. Mantle, J. A. Zeitler and L. F. Gladden, J. Phys. Chem. B, 2014, 118, 10156-10166.

35 J. Keeler, Understanding NMR Spectroscopy, Wiley, Chichester, UK, 2005.

36 K. Hayamizu, S. Tsuzuki and S. Seki, J. Phys. Chem., 2008, 112, 12027-12036.

37 R. C. Remsing, G. Hernandez, R. P. Swatloski, W. W. Massefski, R. D. Rogers and G. Moyna, J. Phys. Chem., 2008, 112, 11071-11078.

38 N. Bloembergen, E. M. Purcell and R. V. Pound, Phys. Rev., 1948, 73, 679-746.

39 T. N Mitchell and B. Costisella, NMR - From Spectra to Structures: An Experimental Approach, Springer-Verlag Berlin, 2007. 